\title{
Hubungan kecemasan, cara persalinan dan onset laktasi dengan kejadian postpartum blues
}

\author{
Greiny Arisani, ${ }^{1 *}$ Noordiati, ${ }^{2}$ \\ ${ }^{1,2}$ Prodi D.III Kebidanan Jurusan Kebidanan Poltekkes Kemenkes Palangka Raya, Indonesia
}

\begin{abstract}
The postpartum period is prone to mental health problems. One of the mental health disorders that occur in mothers postpartum is postpartum blues. Postpartum Blues is the mildest and most common psychopathological manifestation that occurs immediately after delivery that occurs in the first week to 10 days after delivery with a characteristic peak between 3 to 5 days postpartum and decreases in 10 to 12 days thereafter. Postpartum Blues have the potential to be a predictor of depression postpartum and if this condition persists it can lead to more severe mental disorders. This study analyzes the relationship of anxiety, type of giving birth, and lactation onset with postpartum blues. Observational analytic research method with design cross sectional with a data collection tool in the form of a questionnaire. Data analysis used univariat and bivariate analysis using chi square on 122 postpartum mothers who received treatment at the BLUD RSUD dr. Doris Sylvanus Palangka Raya. The results showed $37.7 \%$ of respondents experienced postpartum blues with an EPDS score $\geq$ of 10 . There was a significant relationship between anxiety $(\mathrm{OR}=6.28 ; \mathrm{Cl} 95 \%$ 2.31-16.72; $\mathrm{p}=0.000)$, mode of delivery $(\mathrm{OR}=8.78 ; \mathrm{Cl} 95 \%$ 3.20-24.09; $p=0.000)$ and onset of lactation $(O R=6.42 ; C l 95 \% 2.09-19.74 ; p=0.001)$ with postpartum blues events. It can be concluded Significant relationship of anxiety, mode of delivery, and lactation onset with postpartum Blues at BLUD RSUD Dr. Doris Sylvanus Palangka Raya.
\end{abstract}

Keywords: Postpartum blues; anxiety; type of giving birth; lactation onset

Masa Nifas rentan terhadap masalah kesehatan mental. Salah satu gangguan kesehatan mental yang terjadi pada masa nifas adalah postpartum blues. Postpartum blues merupakan manifestasi pasikopatologis paling ringan dan paling umum terjadi segera setelah melahirkan pada minggu pertama sampai 10 hari setelah melahirkan puncaknya antara 3 sampai 5 hari postpartum dan menurun pada 10 sampai 12 hari sesudahnya. Postpartum blues berpotensi menjadi prediktor depresi postpartum dan jika kondisi ini berlanjut dapat menyebabkan gangguan mental yang lebih parah. Penelitian ini bertujuan untuk menganalisis hubungan kecemasan, cara persalinan dan onset laktasi dengan kejadian postpartum blues. Jenis penelitian ini adalah analitik observasional dengan desain cross sectional dengan alat pengumpul data berupa kuesioner. Analisis data menggunakan analisis univariat dan bivariat menggunakan uji chi square terhadap 122 responden ibu nifas yang mendapatkan perawatan di BLUD RSUD dr. Doris Sylvanus Palangka Raya. Hasil penelitian menunjukkan sebesar 37,7\% responden mengalami postpartum blues dengan skor EPDS $\geq 10$. Terdapat hubungan yang signifikan antara kecemasan $(\mathrm{OR}=6,28 \mathrm{Cl} 95 \% 2,31-$ $16,72 ; p=0,000)$, cara persalinan ( $\mathrm{OR}=8,78 \mathrm{Cl} 95 \% 3,20-24,09 ; \mathrm{p}=0,000)$ dan onset laktasi $(\mathrm{OR}=6,42 \mathrm{Cl}$ $95 \%$ 2,09-19,74; $p=0,001$ dengan kejadian postpartum blues. Dapat disimpulkan terdapat hubungan yang signifikan kecemasan, cara persalinan dan onset laktasi dengan postpartum Blues di BLUD RSUD dr. Doris Sylvanus Palangka Raya.

Kata Kunci: Postpartum blues; kecemasan; cara persalinan; onset laktasi

\footnotetext{
*Corresponding Author: Greiny Arisani (arysanie@gmail.com)
} 


\section{Pendahuluan}

Masa nifas merupakan masa transisi yang vital bagi wanita, bayi baru lahir dan keluarganya yang dimulai setelah melahirkan dan berlangsung sekitar 6 minggu. Periode penting ini memiliki banyak perubahan fisiologis dan psikologis sehingga wanita menyesuaikan diri dengan perubahan dan peran barunya (Almalik, 2017). Selain perubahan fisik ibu nifas juga mengalami perubahan hormonal yang merupakan proses transisi pasikologis yang sangat mendalam (Bayri Bingol et al., 2021).

Periode yang terkait dengan perubahan fisik dan emosional yang intens yang mengarah terhadap kecemasan dan gangguan mood (Manjunath et al., 2011). Setelah melahirkan anak, banyak wanita mengalami penurunan hormon tertentu yang dapat menyebabkan perasaan cemas, stress hingga depresi (Lim, 2021). Hormon estrogen turun 100 hingga 1000 kali lipat selama 3 hingga 4 hari pasca persalinan yang meningkatkan level monoamine oxidase-A (MAO-A) yang berkontribusi menyebabkan postpartum blues (Sacher et al., 2015).

Dalam Sebuah studi menemukan 35\% ibu yang mengalami postpartum blues terjadi pada minggu pertama setelah melahirkan dan $20 \%$ mengalami depresi postpartum terjadi dalam 1 bulan setelah melahirkan (Akbarzadeh et al., 2015). Postpartum blues ditemukan sehubungan dengan gejala ringan dengan tingkat prevalensi berkisar 30\% hingga 75\% setelah melahirkan pada hari ke 3 atau 4 (Idaiani \& Basuki, 2012). Prevalensi postpartum blues dilaporkan 12\%-20\% dan merupakan reaksi normal terhadap kelahiran bayi (Bayri Bingol et al., 2021).

Berdasarkan hasil sistematik review dan meta analisis prevalensi postpartum blues adalah $13,7 \%$ sampai dengan $76 \%$ (Rezaie Keikhaie et al., 2020). Prevalensi postpartum blues di India berada pada kisaran 50\%-60\% (Manjunath et al., 2011). Di Indonesia prevalensi postpartum blues cukup tinggi yaitu $37 \%$ sampai dengan $67 \%$. Postpartum blues cenderung menjadi prediktor depresi pospartum sebesar $15 \%$ menjadi $20 \%$ (Manurung \& Setyowati, 2021).

Kecemasan adalah salah satu yang universal aspek menjadi seorang ibu (Bayri Bingol et al., 2021). Tingkat kecemasan berpengaruh negatif terhadap kualitas hidup postpartum (Daglar et al., 2018). Gangguan kecemasan pascapersalinan merupakan pertanda postpartum blues yang harus diamati pada minggu pertama pascapersalinan (Reck et al., 2009). Hasil studi menunjukan bahwa postpartum blues mendeteksi tekanan psikologis yang salah satu faktor berkontribusi dalam gejala depresi pascapersalinan adalah kecemasan di sekitar persalinan untuk memprediksi psikoemosional pasca persalinan (Zanardo et al., 2020).

Persalinan merupakan pengalaman multidimensi yang disertai dengan berbagai faktor kecemasan dan stress (Bielinski-Blattmann et al., 2016). Faktor persalinan dengan komplikasi dan kurangnya pengetahuan tentang perawatan bayi, postpartum blues juga berpeluang terjadi pada persalinan dengan operasi sesar dan kesulitan menyusui (Ningrum, 2017). Metode persalinan merupakan salah satu faktor resiko 
postpartum blues dan masalah kesehatan mental ibu. Operasi seksio sesar merupakan faktor resiko potensial gangguan emosional pada wanita selama periode sebelum dan sesudah kelahiran dan tingkat nyeri merupakan penanda potensi keparahannya (llska et al., 2020).

Ketidakstabilan emosi terjadi pada wanita setelah persalinan baik persalinan pervaginam maupun persalinan dengan operasi seksio sesar, namun ketidakstabilan emosi lebih sedikit sering dialami setelah operasi seksio sesar (Pius Kamsu Moyo \& Djoda, 2020). Sebagian besar wanita melaporkan rasa sakit yang hebat meskipun mendapat dukungan yang baik dari petugas kesehatan. Wanita dengan reaksi stress akut melaporkan lebih banyak perasaan kecemasan dan disorientasi dan kurang percaya diri selama proses kelahiran (Bielinski-Blattmann et al., 2016).

Faktor resiko postpartum blues yang dialami wanita pada periode awal postpartum adalah kesulitan dan penghentian menyusui selanjutnya adalah durasi menyusui yang pendek atau tidak menyusui telah dikaitkan dengan postpartum blues (Koutra et al., 2018). Kesulitan dalam menyusui juga menyebabkan depresi pada ibu postpartum kesulitan-kesulitan ini termasuk puting susu lecet, kelelahan dan khawatikan dikarenakan ASI tidak keluar pasca salin (KendallTackett, 2007). Postpartum blues dapat menganggu perawatan bayi dan meningkatkan resiko gejala postpartum depresi, gangguan interaksi ibu dan bayi dan mempengaruhi perkembangan anak (Rezaie Keikhaie et al., 2020). Postpartum blues lebih ringan dari depresi postpartum sedangkan psikosis postpartum diklasifikasikan sebagai gangguan jiwa berat (Idaiani \& Basuki, 2012).

Postpartum blues cenderung menjadi prediktor depresi pospartum (Manurung \& Setyowati, 2021) yang dapat mempengaruhi perkembangan bayi karena berkurangnya kapasitas pengasuhan anak dan efek jangka panjang adalah masalah prilaku, kesehatan emosional, fisik serta keterlambatan kognitif yang dikaitkan dengan interaksi awal yang terganggu (Kokkinaki, 2015). Selain itu jika kondisi ini berlanjut dapat mengakibatkan gangguan mental yang lebih parah (Idaiani \& Basuki, 2012). Penelitian ini bertujuan untuk menganalisis hubungan kecemasan, cara persalinan dan onset laktasi dengan kejadian postpartum blues di BLUD RSUD dr. Doris Sylvanus Palangka Raya.

\section{Metode}

Penelitian ini adalah penelitian kuantitatif dengan jenis penelitian analitik observasional desain cross sectional. Populasi penelitian ini adalah seluruh ibu nifas yang melahirkan dan mendapatkan perawatan postpartum di BLUD RSUD dr. Doris Sylvanus Palangka Raya. Teknik pengambilan sampel menggunakan consecutive sampling dengan pertimbangan pemilihan sampel yang memenuhi kriteria inklusi, yaitu ibu dalam masa early postpartum (hari ke-3 sampai dengan hari ke 7) pasca salin dan bersedia menjadi responden. Kriteria ekslusi pada penelitian ini adalah komplikasi masa nifas, gangguan kesadaran dan tidak kooperatif. Besar sampel penelitian ini adalah 122 responden.

Penelitian ini menggunakan data primer dilakukan dengan menggunakan instrumen 
berupa kuesioner yang berisi identitas responden, umur responden, paritas, pendidikan, pekerjaan, onset laktasi, cara persalinan, Kuesioner postpartum blues menggunakan kuesioner Edinburgh postpartum depression scale (EPDS) dan kuesioner kecemasan menggunakan kuesioner zung self rating anxiety scale (ZSRAS).

Analisis data menggunakan analisis univariat, bivariat dan multivariat. Untuk Analisis bivariat menggunakan uji chi square kemudian analisis multivariat menggunakan uji regresi linier logistik variabel yang memenuhi syarat dengan nilai $p$ value $<0,25$.

\section{Hasil dan Pembahasan}

Hasil analisis kejadian postpartum blues, kecemasan, cara persalinan dan onset laktasi ditampilkan pada tabel dibawah ini :

Tabel 1. Distribusi Frekuensi Kejadian Postpartum Blues, Kecemasan, Cara Persalinan dan Onset Laktasi pada Ibu Nifas di BLUD RSUD dr. Dorsi Sylvanus Palangka Raya $(n=122)$

\begin{tabular}{lcrccc}
\hline \multicolumn{1}{c}{ Variabel } & $\mathrm{N}$ & \multicolumn{1}{c}{ Kriteria } & Frekuensi & Persentase \\
\hline Postpartum Blues & 122 & 1. & Mengalami postpartum blues & 46 & $37,7 \%$ \\
& & 2. & Tidak mengalami postpartum blues & 76 & $62,3 \%$ \\
\hline Kecemasan & 122 & 1. & Cemas & 35 & $28,7 \%$ \\
& & 2. & Tidak Cemas & 87 & $71,3 \%$ \\
\hline Cara Persalinan & 122 & 1. & Perabdominal & 61 & $50 \%$ \\
& & 2. Spontan Pervaginam & 61 & $50 \%$ \\
\hline Onset Laktasi & 122 & 1. & Onset Laktasi Tertunda & 48 & $39,3 \%$ \\
& & 2. & Normal Laktasi & 74 & $60,7 \%$ \\
\hline
\end{tabular}

Pada tabel 1 sebanyak 46 responden (37,7\%) mengalami postpartum blues sebanyak 76 responden $(62,3 \%)$ tidak mengalami postpartum blues. Kemudian sebanyak 35 responden (28,7\%) mengalami kecemasan dan sebanyak 87 responden $(71,3 \%)$ tidak cemas. Sebanyak 61 responden $(50 \%)$ bersalin secara perabdominal dan sebesar 61 responden (50\%) bersalin secara spontan pervaginam. Sebagian responden mengalami normal laktasi, yaitu sebanyak 74 responden $(60,7 \%)$.

Tabel 2. Hubungan Kecemasan, Cara Persalinan dan Onset Laktasi dengan Kejadian Postpartum Blues pada Ibu Nifas di BLUD RSUD dr. Dorsi Sylvanus Palangka Raya

\begin{tabular}{|c|c|c|c|c|c|}
\hline \multirow{2}{*}{ Variabel } & \multicolumn{2}{|c|}{ Postpartum Blues } & \multirow{2}{*}{ p value } & \multirow{2}{*}{ OR } & \multirow{2}{*}{ Cl 95\% } \\
\hline & Postpartum Blues & Tidak Postpartum Blues & & & \\
\hline \multicolumn{6}{|l|}{ Kecemasan } \\
\hline 1. Cemas & $18(39,1 \%)$ & $17(22,4 \%)$ & 0,047 & 2,231 & $1,001-4,971$ \\
\hline 2. Tidak Cemas & $28(60,9 \%)$ & $59(77,6 \%)$ & & & \\
\hline \multicolumn{6}{|l|}{ Cara Persalinan } \\
\hline 1. Perabdominal & $35(76,1 \%)$ & $26(34,2 \%)$ & 0,000 & 6,119 & $2,677-13,987$ \\
\hline 2. Spontan Pervaginam & $11(23,9 \%)$ & $50(65,8 \%)$ & & & \\
\hline \multicolumn{6}{|l|}{ Onset Laktasi } \\
\hline 1. Onset Laktasi Tertunda & $31(67,4 \%)$ & $17(22,4 \%)$ & 0,000 & 7,173 & $3,162-16,272$ \\
\hline 2. Normal Laktasi & $15(32,6 \%)$ & $59(77,6 \%)$ & & & \\
\hline
\end{tabular}


Tabel 2 pada variabel kecemasan sebanyak 18 responden $(39,1 \%)$ dengan kategori cemas mengalami postpartum blues dan sebanyak 17 responden $(22,4 \%)$ dengan kategori tidak cemas tidak mengalami potpartum blues. Hasil analisis statistik disimpulkan bahwa terdapat hubungan yang signifikan antara kecemasan ( $\mathrm{p}$ value $0,047<0,05$ ) dengan kejadian postpartum blues di BLUD RSUD dr. Doris Sylvanus Palangka Raya.

Hasil studi menunjukan bahwa postpartum blues mendeteksi tekanan psikologis yang salah satu faktor berkontribusi dalam gejala depresi pascapersalinan adalah kecemasan di sekitar persalinan untuk memprediksi psikoemosional pasca persalinan (Zanardo et al., 2020). Hasil penelitian ini menyimpulkan bahwa ibu nifas yang mengalami kecemasan mempunyai kemungkinan 2,231 kali untuk mengalami postpartum blues dibandingkan ibu nifas yang tidak mengalami kecemasan.

Peningkatan kortisol selama kehamilan memicu kecemasan pada postpartum karena hipokortisolemia dimana korteks adrenal mengeluarkan lebih sedikit kortisol daripada yang dibutuhkan. Pola khas kadar kortisol pada kehamilan akan memuncak pada saat persalinan dan menurun tajam ke tingkat awal dalam 3 hari pertama pasca persalinan (Seth et al., 2016).

Skor tinggi pada kecemasan pada masa postpartum dapat menganggu kehidupan wanita terutama terhadap perkembangan anak. Studi terbaru menunjukkan bahwa skor EPDS yang tinggi terutama karena gejala cemas pasca salin menganggu keberhasilan laktasi. Secara khusus gejala kecemasan pasca salinterkait dengan postpartum blues atau depresi atipikal sedangkan gejala depresi yang terjadi setelah 2 hari pasca salin menunjukkan resiko lebih tinggi mengalami gangguan depresi dikemudian hari (Petrozzi \& Gagliardi, 2013).

Pada variabel cara persalinan sebagian besar reponden yang bersalin secara seksio sesar mengalami postpartum blues dan sebagian besar responden yang bersalin secara spontan pervaginam sebagian besar tidak mengalami postpartum blues. Hasil uji statistik terdapat hubungan yang signifikan antara cara persalinan ( $p$ value $0,000<0,05$ ) dengan kejadian postpartum blues di BLUD RSUD dr. Doris Sylvanus Palangka Raya. Ibu nifas dengan cara persalinan perabdominal mempunyai kemungkinan 6,119 kali untuk mengalami postpartum blues dibandingkan ibu nifas yang bersalin spontan pervaginam.

Metode persalinan merupakan salah satu faktor resiko postpartum blues dan masalah kesehatan mental ibu. Operasi seksio sesarea merupakan faktor resiko potensial gangguan emosional pada wanita selama periode sebelum dan sesudah kelahiran (Ilska et al., 2020). Hasil metanalisis menunjukan bahwa operasi seksio sesarea dan emergensi seksio sesarea meningkatkan resiko depresi postpartum (Xu et al., 2017). Penggunaan analgesik epidural mengarah kepada pengurangan yang signifikan dari sindrom nyeri dan respon stress selama persalinan yang meningkatkan resiko postpartum blues pada periode awal pasca persalinan tetapi sedikit mempengaruhi kejadian depresi postpartum (Riazanova et al., 2018). 
Hasil penelitian lain menyimpulkan bahwa wanita yang meminta seksio sesarea memiliki tingkat depresi dan kecemasan antepartum yang lebih tinggi tetapi tidak mengalami depresi pasca melahirkan dibandingkan wanita yang melahirkan pervaginam. Satu studi meneliti efek seksio sesarea pada wanita yang sebelumnya bersalin pervaginam memiliki tingkat gejala gangguan stress pasca trauma dan depresi yang jauh lebih tinggi daripada wanita dengan persalinan pervaginam (Olieman et al., 2017).

Stress dan tekanan psikologis menetap pada wanita dari trimester ketiga kehamilan hingga 46 bulan pasca persalinan dan cenderung terjadi dalam konteks persalinan seksio sesar, masalah tidur ibu, masalah kesehatan anak dan peristiwa yang penuh tekanan (Clout \& Brown, 2015). Persalinan pervaginam mengarah kepada kesehatan fisik yang lebih baik pada 2 bulan setelah melahirkan dan kesehatan mental pada 4 bulan setelah melahirkan dibandingkan dengan seksio sesaria. Upaya harus silakukan untuk mengurangi seksio sesarea (Sadat et al., 2013).

Onset laktasi adalah inisiasi produksi susu dalam jumlah besar pada kelenjar susu yang diukur dengan menggambarkan payudara keras, penuh dan berat dan keluarnya ASI atau cairan kental kekuningan yang disebut kolostrum yang dianggap sebagai titik waktu ketika ASI benarbenar masuk dan merupakan indikator valid dari laktogenesis tahap II. Peningkatan produksi ASI signifikan antara 24-48 jam pasca persalinan dan persepsi onset laktasi setalah 72 jam pasca persalinan dianggap tertunda (Piesesha et al., 2018).
Pada variabel onset laktasi sebagian besar responden yang onset laktasinya tertunda mengalami postpartum blues dan sebagian besar responden yang normal laktasi tidak mengalami postpartum blues. Hasil uji statistik terdapat hubungan yang signifikan antara onset laktasi ( $p$ value $0,000<0,05$ ) dengan kejadian postpartum blues di BLUD RSUD dr. Doris Sylvanus Palangka Raya.

Durasi menyusui dikaitkan dengan Postpartum blues sampai terjadinya depresi postpartum. Identifikasi faktor resiko penghentian menyusui dini merupakan prioritas kesehatan, skrining depresi selama kehamilan dapat menjadi alat yang berguna untuk mengidentifikasi wanita yang beresiko untuk durasi menyusui yang lebih pendek, postpartum blues sampai dengan depresi pascapersalinan (Castro \& Figueiredo, 2015).

Prolaktin diduga memiliki peran dalam terjadinya perasaan cemas, depresi dan sifat kasar. Beberapa alasan onset laktasi tertunda pasca salin, yaitu kelahiran yang sangat traumatis, penggunaan vakum, forcep atau operasi seksio sesarea akan mempengaruhi kadar hormon stress yang dapat menyebabkan penundaan pengeluaran ASI, cairan intravena dalam jumlah besar yang digunakan selama kelahiran, perdarahan postpartum, pemberian obat penghilang rasa sakit saat persalinan yang dikaitkan dengan onset laktasi tertunda dan stress yang disebabkan oleh proses persalinan sehingga mempengaruhi onset laktasi dapat menyebabkan postpartum blues (Pearson-Glaze, 2021). 
Kemudian wanita yang mengalami stress atau kecemasan selama persalinan cenderung memiliki onset laktasi yang tertunda (Piesesha et al., 2018). Menurut studi ibu yang menderita gejala depresi mungkin mengalami kurang percaya diri dalam kemampuannya menyusui sehingga diperlukan prosedur screening untuk mendeteksi depresi akibat pemberian ASI yang tidak memuaskan (Zubaran \& Foresti, 2013).
Wanita yang beresiko mengalami onset laktasi tertunda memerlukan dukungan menyusui tambahan selama minggu pertama pasca salin. Bila pengeluaran ASI terlambat maka diketahui adanya onset laktasi tertunda. Ibu dengan onset laktasi tertunda lebih cenderung mendapat tekanan sehingga menganggu refleks let down sehingga menyebabkan peningkatan kecemasan dan stress yang berpengaruh terhadap pemberian ASI (Pearson-Glaze, 2021).

Tabel 3. Analisis Multivariat Kecemasan, Cara Persalinan dan Onset Laktasi dengan Kejadian Postpartum Blues di BLUD RSUD dr. Doris Sylvanus Palangka Raya

\begin{tabular}{|c|c|c|c|c|}
\hline Variabel & R square & $\operatorname{Exp}(\mathrm{B})$ & $\mathrm{Cl} 95 \%$ & $\mathrm{p}$ value \\
\hline Kecemasan & & 6,288 & $2,319-16,721$ & 0,000 \\
\hline Cara Persalinan & 0,451 & 8,789 & $3,206-24,095$ & 0,000 \\
\hline Onset Laktasi & & 6,425 & $2,090-19,746$ & 0,001 \\
\hline
\end{tabular}

Berdasarkan hasil penelitian diketahui bahwa variabel kecemasan, cara persalinan dan onset laktasi berhubungan dengan kejadian postpartum blues. Kemudian nilai koefisien determinasi ( $R$ square) sebesar 0,451 sehingga dapat disimpulkan bahwa variabel kecemasan, cara persalinan dan onset laktasi memiliki pengaruh sebesar $45,1 \%$ dengan kejadian postpartum blues dan 54,9\% dipengaruhi oleh faktor lain. Variabel cara persalinan merupakan variabel yang paling dominan dengan kejadian postpartum blues bersama variabel kecemasan dan onset laktasi.

Studi epidemiologi menemukan hubungan yang kuat antara postpartum blues dan postpartum depresi yang dapat berkisar dari 20 hingga $40 \%$, beberapa laporan berfokus pada kemungkinan faktor resiko yang dapat mendukung timbulnya postpartum blues, yaitu faktor obstetri, psikologis dan sosial. Faktor resiko obstetrik yang penting salah satunya adalah operasi seksio sesarea, kecemasan dan riwayat depresi sebelumnya dapat mengakibatkan faktor resiko psikologis bersama-sama dengan timbulnya gejala psikologis selama kehamilan atau menderita postpartum depresi. Faktor sosial terkait dengan gejala suasana hati yang semakin tertekan setelah persalinan (Gerli et al., 2019).

Faktor resiko postpartum blues yang dialami wanita pada periode awal postpartum adalah kesulitan dan penghentian menyusui selanjutnya adalah durasi menyusui yang pendek atau tidak menyusui telah dikaitkan dengan postpartum blues (Koutra et al., 2018). Postpartum blues dapat menganggu perawatan bayi dan meningkatkan resiko gejala postpartum depresi, gangguan interaksi ibu dan bayi dan mempengaruhi perkembangan anak (Rezaie Keikhaie et al., 2020). 
Postpartum blues lebih ringan dari depresi postpartum sedangkan psikosis postpartum diklasifikasikan sebagai gangguan jiwa berat (Idaiani \& Basuki, 2012). Ibu dengan depresi pasca persalinan akan sulit untuk merawat anak dan menyebabkan gangguan interaksi antara ibu dan bayi seperti persepsi negatif tentang perilaku bayi yang telah dikaitkan dengan attachment insecurity pada anak. Oleh karena itu ketidakstabilan mental pada ibu pasca persalinan dianggap sebagai masalah kesehatan masyarakat yang kritis (Takahashi \& Tamakoshi, 2014).

\section{Kesimpulan}

Hasil penelitian menyimpulkan terdapat hubungan yang signifikan antara kecemasan, cara persalinan dan onset laktasi dengan kejadian postpartum blues di BLUD RSUD dr. Doris Sylvanus Palangka Raya. Variabel kecemasan, cara persalinan dan onset laktasi mempunyai pengaruh yang signifikan terhadap kejadian postpartum blues. Kemudian nilai koefisien determinasi sebesar 0,451 sehingga dapat disimpulkan bahwa variabel kecemasan, cara persalinan dan onset laktasi memiliki pengaruh kontribusi sebesar $45,1 \%$ terhadap kejadian postpartum blues dan sebesar $54,9 \%$ dipengaruhi oleh faktor lain. Variabel cara persalinan merupakan variabel yang paling dominan dengan kejadian postpartum blues bersama variabel kecemasan dan onset laktasi.

\section{Daftar Pustaka}

Akbarzadeh, M., Mokhtaryan, T., Amooee, S., Moshfeghy, Z., \& Zare, N. (2015). Investigation of the effect of religious doctrines on religious knowledge and attitude and postpartum blues in primiparous women. Iranian Journal of Nursing and Midwifery Research, 20(5), 570576. https://doi.org/10.4103/17359066.164586

Almalik, M. M. (2017). Understanding Maternal Postpartum Needs: A Descriptive Survey of Current Maternal Health Services. International Journal of Laboratory Hematology, 26(23-24), 4654-4663. https://doi.org/https://doi.org/10.1111/jocn .13812

Bayri Bingol, F., Bal, M. D., Aydin Ozkan, S., Zengin, O., \& Civ, B. (2021). The adaptation of the Postpartum-Specific Anxiety Scale into the Turkish language. Journal of Reproductive and Infant Psychology, 39(1), 86-99. https://doi.org/10.1080/02646838.2019.170 5265

Bielinski-Blattmann, D., Gürber, S., Lavallee, K., Grob, A., Surbek, D., \& Stadlmayr, W. (2016). Labour experience and postpartum stress and depression: a quantitative and qualitative examination. Journal of Reproductive and Infant Psychology, 34(2), 162-174.

https://doi.org/10.1080/02646838.2015.113 1252

Castro, C., \& Figueiredo, B. (2015). Breastfeeding and depression : A systematic review of the literature. 171, 142-154. https://doi.org/10.1016/j.jad.2014.09.022

Clout, D., \& Brown, R. (2015). Sociodemographic, pregnancy, obstetric, and postnatal predictors of postpartum stress, anxiety and depression in new mothers. Journal of Affective Disorders, 188, 60-67. https://doi.org/10.1016/j.jad.2015.08.054

Daglar, G., Bilgic, D., \& Aydın Özkan, S. (2018). Depression, Anxiety and Quality of Life of 
Mothers in the Early Postpartum Period. International Journal of Behavioral Sciences, 11(4), 152-159.

Gerli, S., Fraternale, F., Lucarini, E., Chiaraluce, S., Tortorella, A., Bini, V., Giardina, I., Moretti, P., Gerli, S., Fraternale, F., Lucarini, E., Chiaraluce, S., Tortorella, A., Bini, V., Giardina, I., Moretti, P., \& Favilli, A. (2019). Obstetric and psychosocial risk factors associated with maternity blues. The Journal of Maternal-Fetal \& Neonatal Medicine, $O(0)$, $1-6$.

https://doi.org/10.1080/14767058.2019.163 0818

Idaiani, S., \& Basuki, B. (2012). Postpartum depression in Indonesia women: a national study. Health Science Journal of Indonesia, 3(1), 3-8. https://doi.org/10.22435/hsji.v3i1Jun.396.38

Ilska, M., Banaś, E., Gregor, K., Brandt-Salmeri, A., Ilski, A., \& Cnota, W. (2020). Vaginal delivery or caesarean section - Severity of early symptoms of postpartum depression and assessment of pain in Polish women in the early puerperium. Midwifery, 87. https://doi.org/10.1016/j.midw.2020.10273 1

Kendall-Tackett, K. (2007). A new paradigm for depression in new mothers: The central role of inflammation and how breastfeeding and anti-inflammatory treatments protect maternal mental health. International Breastfeeding Journal, 2, 1-14. https://doi.org/10.1186/1746-4358-2-6

Kokkinaki, T. (2015). Maternal and Paternal Postpartum Depression: Effects on Early Infantparent Interactions. Journal of Pregnancy and Child Health, 03(01), 1-5. https://doi.org/10.4172/2376127x.1000e126

Koutra, K., Vassilaki, M., Georgiou, V., Koutis, A., Bitsios, P., Kogevinas, M., \& Chatzi, L. (2018). Pregnancy, perinatal and postpartum complications as determinants of postpartum depression: The Rhea motherchild cohort in Crete, Greece. Epidemiology and Psychiatric Sciences, 27(3), 244-255. https://doi.org/10.1017/S204579601600106 2

Lim, G. (2021). Perinatal depression. Current Opinion in Anaesthesiology, 34(3), 233-237. https://doi.org/10.1097/ACO.00000000000 00998

Manjunath, N., Venkatesh, G., \& Rajanna. (2011). Postpartum blue is common in socially and economically insecure mothers. Indian Journal of Community Medicine, 36(3), 231$233 . \quad$ https://doi.org/10.4103/09700218.86527

Manurung, S., \& Setyowati, S. (2021). Development and validation of the maternal blues scale through bonding attachments in predicting postpartum blues. Malaysian Family Physician, 16(1), 64-74. https://doi.org/10.51866/oa1037

Ningrum, S. P. (2017). Faktor-Faktor Psikologis yang Mempengaruhi Postpartum Blues. Psympathic: Jurnal Ilmiah Psikologi, 4(2), 205-218. https://doi.org/10.15575/psy.v4i2.1589

Olieman, R. M., Siemonsma, F., Bartens, M. A., Garthus-niegel, S., \& Scheele, F. (2017). The effect of an elective cesarean section on maternal request on peripartum anxiety and depression in women with childbirth fear : a systematic review. 21-23. https://doi.org/10.1186/s12884-017-1371-z 
Pearson-Glaze, P. (2021). No Breast Milk After Delivery. https://breastfeeding.support/nobreast-milk-after-delivery/

Petrozzi, A., \& Gagliardi, L. (2013). Review article Anxious and depressive components of Edinburgh Postnatal Depression Scale in maternal postpartum psychological problems 1 ). 41(4), 343-348. https://doi.org/10.1515/jpm-2012-0258

Piesesha, F., Purnomo, W., Irawan, R., Health, C., \& Disease, M. (2018). Maternal Parity and Onset of Lactation on Postpartum Mothers. 2(2), 249-251.

Pius Kamsu Moyo, G., \& Djoda, N. (2020). The Emotional Impact of Mode of Delivery in Cameroonian Mothers: Comparing Vaginal Delivery and Caesarean Section. American Journal of Psychiatry and Neuroscience, 8(1), 22. https://doi.org/10.11648/j.ajpn.20200801.1 5

Reck, C., Stehle, E., Reinig, K., \& Mundt, C. (2009). Maternity blues as a predictor of DSM-IV depression and anxiety disorders in the first three months postpartum. Journal of Affective Disorders, 113(1-2), 77-87. https://doi.org/10.1016/j.jad.2008.05.003

Rezaie Keikhaie, K., Arbabshastan, M. E., Rafiemanesh, H., Amirshahi, M., Mogharabi, S., \& Sarjou, A. A. (2020). Prevalence of the Maternity Blues in the Postpartum Period. Journal of Obstetric, Gynecologic \& Neonatal Nursing, February, 1-10.

Riazanova, O. V., Alexandrovich, Y. S., \& loscovich, A. M. (2018). The relationship between labor pain management, cortisol level and risk of postpartum depression development: A prospective nonrandomized observational monocentric trial. Romanian Journal of Anaesthesia and Intensive Care, 25(2), 123-
130.

https://doi.org/10.21454/rjaic.7518.252.rzn

Sacher, J., Rekkas, P. V., Wilson, A. A., Houle, S., Romano, L., Hamidi, J., Rusjan, P., Fan, I., Stewart, D. E., \& Meyer, J. H. (2015). Relationship of monoamine oxidase-A distribution volume to postpartum depression and postpartum crying. Neuropsychopharmacology, 40(2), 429-435. https://doi.org/10.1038/npp.2014.190

Sadat, Z., Taebi, M., Saberi, F., \& Kalarhoudi, M. A. (2013). The relationship between mode of delivery and postpartum physical and mental health related quality of life. 18(6).

Seth, S., Lewis, A. J., \& Galbally, M. (2016). Perinatal maternal depression and cortisol function in pregnancy and the postpartum period: $A$ systematic literature review. BMC Pregnancy and Childbirth, 16(1). https://doi.org/10.1186/s12884-016-0915-y

Takahashi, Y., \& Tamakoshi, K. (2014). Factors associated with early postpartum maternity blues and depression tendency among Japanese mothers with full-term healthy infants. Nagoya Journal of Medical Science, 76(1-2), 129-138. https://doi.org/10.18999/nagjms.76.1-2.129

Xu, H., Ding, Y., Ma, Y., Xin, X., \& Zhang, D. (2017). Cesarean section and risk of postpartum depression: A meta-analysis. Journal of Psychosomatic Research, 97, 118-126. https://doi.org/10.1016/j.jpsychores.2017.0 4.016

Zanardo, V., Volpe, F., de Luca, F., Giliberti, L., Giustardi, A., Parotto, M., Straface, G., \& Soldera, G. (2020). Maternity blues: a risk factor for anhedonia, anxiety, and depression components of Edinburgh Postnatal Depression Scale. Journal of Maternal-Fetal and Neonatal Medicine, 
33(23),

3962-3968.

https://doi.org/10.1080/14767058.2019.159

3363

Zubaran, C., \& Foresti, K. (2013). Sexual \& Reproductive Healthcare The correlation between breastfeeding self-efficacy and maternal postpartum depression in southern Brazil. Sexual \& Reproductive Healthcare, 4(1), 9-15. https://doi.org/10.1016/j.srhc.2012.12.001 
This page itentionally left blank. 